\title{
Editorial: Tyger and Kestrel
}

The little dog laughed to see such sport. The cow jumped over the moon. The fox knows many things, the hedgehog knows one great thing. Are you washed in the blood of the Lamb? Are you marked with the mark of the Beast? 'Tyger, Tyger, Beauty and the Beast, the Hound of Heaven, Squirrel Nutkin; snakes in the grass, flies in amber or the ointment; Three Bears, Pooh Bear, Great Bear; the Big Bad Wolf in sheep's clothing, the dog in the manger, the Lion and the Unicorn: wherever we turn in our language or literature or imagination we find the beasts of the field, the fowls of the air, fish, flesh and good red herring. We find them in literature because we find them in life. Aesop and Orwell, Swift and Carroll, Hobbes and Plato all speak to us of the familiar denizens of our farms and firesides, zoos and circuses. Though they speak of what is familiar they may still reveal something new, making us see what we have seen too often to be able to see it steadily or see it whole. Sometimes they speak of what we have seen too often to be able to see it at all, and can startle us by telling us what we have always known: that we are animals, mammals, predators or pests.

Questions about animals and their relations with human animals have in recent years engaged the attention of a growing number of philosophers. Some of them have been concerned to influence the conduct of their readers by presenting argument and evidence about what goes on in factory farms, slaughterhouses and research laboratories. Professor John Benson, in the course of writing his article 'Duty and the Beast', has become a vegetarian. But he and the other contributors to this issue show that the debate must range more widely if it is to do justice to the variety of the questions and considerations that arise in this field. The emphasis of Peter Singer and Tom Regan has been on animal suffering and human cruelty. We are reminded by Cora Diamond that the case against meateating need not rest on utilitarian premises. If animals for the table were comfortably housed and painlessly slaughtered they would still be sacrificing their lives to the needs or whims of a predator species. At least some non-human animals, she argues, are to be regarded as our fellow creatures, to be eaten, if at all, only under the extreme circumstances that might also overcome our revulsion against cannibalism. Leslie Pickering Francis and Richard Norman insist that some animals are more equal than others, and that we must take account of our relationships with individuals and species. They and Philip E. Devine suggest that even on the utilitarian ground chosen by many vegetarians the comparisons of utilities and predictions of consequences are less straightforward than the more enthusiastic reformers have supposed. There is a danger of forgetting how much 


\section{Editorial}

satisfaction of how many human interests and needs may have to be set against the loss of bovine, ovine and porcine life, liberty and happiness.

Gareth B. Matthews and J. L. Mackie, though they pay attention to developments in the relevant natural sciences, are dealing with topics that have remained on the agenda of philosophy at times when philosophers were less concerned than they are today to relate their work to other fields and to issues of moral choice and social policy. When Professor Matthews pleads for a recognition of the unity of psychology he is contributing primarily to the discussion of an abstract question in the philosophy of mind, and yet his argument and conclusion are parallel with those of Cora Diamond on the unity of the family of living creatures, the omne animal of Psalm 145. Mr Mackie's paper shows that there is scope for philosophical assistance to be given to those who are engaged at first hand in the progress of the biological sciences, and also that results achieved in specialized scientific research may be relevant to, even when they cannnot be expected to settle, ethical and philosophical controversies like those between Nietzsche and his Christian critics.

Mary Midgley had already shown by her article 'The Concept of Beastliness' (Philosophy, April 1973) how wide was her understanding of the scope of the problems of animal and human nature, and how widely she could range in search of light to cast upon them. The article has now formed the basis for Part One of her book Beast and Man: The Roots of Human Nature, published this month by Cornell University Press and soon to be published here by Harvester Press. She too takes account of the sciences of life, including ethology and sociobiology. She invokes the help of Kant and Aristotle, asks what it is to be scientific about people and animals, rebukes the folly of trying to understand us while at the same time denying that we have a nature to be understood. The book is full of thoughts of her own and thoughts of others on Instinct, Purpose, Motives, Facts and Values, Rationality, Culture, the Unity of Life. It is valuable for all these thoughts and themes, and especially because it brings to them and to the integration of them the long perspective, the literary imagination, the philosophical realism to know that even the creatures that we are justified in using are not to be seen as existing only to be means to our ends. This lesson, which is taught by Blake's Tyger, is expounded by Mrs Midgley between the lines of her book as well as in this passage where she quotes another artist seeing another creature as what it is and not another thing:

In The Sovereignty of Good Iris Murdoch writes, 'I am looking out of my window in an anxious and resentful state of mind, brooding perhaps on some damage done to my prestige. Then suddenly I observe a hovering kestrel. In a moment everything is altered. The brooding self with its hurt vanity has disappeared. There is nothing now but kestrel. And when I return to thinking of the other matter it seems less important. 
Certainly we could (she goes on) think of this as a measure of mental hygiene, regard the kestrel as a device for regaining balance. But there is something perverse about doing so; 'More naturally, as well as more properly, we take a self-forgetful pleasure in the sheer, alien pointless independent existence of animals, birds, stones and trees.' This has to be right, because the release itself depends on the kestrel's not being such a device. If we found that we were in Disneyland, with plastic kestrels going up at carefully randomized intervals, the entire point would be lost. 